\title{
Erratum to: Consistent LDA' + DMFT-an Unambiguous Way to Avoid Double Counting Problem: NiO Test
}

\author{
I. A. Nekrasov ${ }^{a, *}$, N. S. Pavlov ${ }^{a, * *}$, and M. V. Sadovskii ${ }^{a, b, * * *}$ \\ ${ }^{a}$ Institute of Electrophysics, Ural Branch, Russian Academy of Sciences, Yekaterinburg, 620016 Russia \\ ${ }^{b}$ Institute of Metal Physics, Ural Branch, Russian Academy of Sciences, Yekaterinburg, 620990 Russia \\ *e-mail: nekrasov@iep.uran.ru \\ **e-mail:pavlov@iep.uran.ru \\ ***e-mail: sadovski@iep.uran.ru \\ Received April 19, 2019; accepted April 19, 2019
}

DOI: $10.1134 / \mathrm{S} 0021364019050151$

The name of the second author should read N. S. Pavlov

The original article can be found online at https://doi.org/10.1134/S0021364012110070. 